\title{
Thermodynamic analysis of steam reforming of glycerol for hydrogen production at atmospheric pressure
}

\author{
Ammaru Ismaila ${ }^{1}$, Xueli Chen ${ }^{2}$, Xin Gao $(\varangle)^{1,3}$, Xiaolei Fan $(\bowtie)^{1}$ \\ 1 Department of Chemical Engineering and Analytical Science, School of Engineering, The University of Manchester, Manchester M13 9PL, UK \\ 2 Institute of Clean Coal Technology, East China University of Science and Technology, Shanghai 200237, China \\ 3 School of Chemical Engineering and Technology, National Engineering Research Center of Distillation Technology, Collaborative Innovation \\ Center of Chemical Science and Engineering (Tianjin), Tianjin University, Tianjin 300072, China
}

(C) The Author(s) 2020. This article is published with open access at link.springer.com and journal.hep.com.cn

\begin{abstract}
Thermodynamic chemical equilibrium analysis of steam reforming of glycerol (SRG) for selective hydrogen production was performed based on the Gibbs free energy minimisation method. The ideal SRG reaction $\left(\mathrm{C}_{3} \mathrm{H}_{8} \mathrm{O}_{3}+3 \mathrm{H}_{2} \mathrm{O} \rightarrow 3 \mathrm{CO}_{2}+7 \mathrm{H}_{2}\right)$ and a comprehensive set of side reactions during SRG are considered for the formation of a wide range of products. Specifically, this work focused on the analysis of formation of $\mathrm{H}_{2}, \mathrm{CO}_{2}, \mathrm{CO}$ and $\mathrm{CH}_{4}$ in the gas phase and determination of the carbon free region in SRG under the conditions at atmospheric pressure, $600 \mathrm{~K}-1100 \mathrm{~K}$ and $1.013 \times 10^{5}-1.013 \times 10^{6} \mathrm{~Pa}$ with the steam-to-glycerol feed ratios (SGFR) of 1:5-10. The reaction conditions which favoured SRG for $\mathrm{H}_{2}$ production with minimum coke formation were identifies as: atmospheric pressure, temperatures of $900 \mathrm{~K}-1050 \mathrm{~K}$ and SGFR of 10:1. The influence of using the inert carrier gas (i.e., $\mathrm{N}_{2}$ ) in SRG was studied as well at atmospheric pressure. Although the presence of $\mathrm{N}_{2}$ in the stream decreased the partial pressure of reactants, it was beneficial to improve the equilibrium yield of $\mathrm{H}_{2}$. Under both conditions of SRG (with/without inert gas), the $\mathrm{CH}_{4}$ production is minimised, and carbon formation was thermodynamically unfavoured at steam rich conditions of SGFR > 5:1.
\end{abstract}

Keywords steam reforming of glycerol, $\mathrm{H}_{2}, \mathrm{~N}_{2}$, carbon deposition, thermodynamic analysis, Gibbs free energy minimisation

Received February 29, 2020; accepted June 15, 2020

E-mails: gaoxin@tju.edu.cn (Gao X); xiaolei.fan@manchester.ac.uk (Fan X)

\section{Introduction}

The quest for alternatives to dwindling conventional energy sources has made biomass resources as potential raw materials for the generation of sustainable platform chemicals, fuels and energies. Nowadays, biomass used for conversion technologies (to produce value-added energy carriers such as bio-oils and $\mathrm{H}_{2}$ ) is primarily produced from wastes (such as wood waste, agricultural waste and municipal solid waste), which would otherwise be disposed via landfill disposal, having environmental impact. Among the mature conversion technologies, the production of biodiesel via the transesterification of various oils/fats has been adopted by industry to produce sustainabale fuel to increase the energy security of the society. The main by-product from the transesterification process for biodiesel production is glycerol $\left(\mathrm{C}_{3} \mathrm{H}_{8} \mathrm{O}_{3}\right.$, i.e., $100 \mathrm{~kg}$ of glycerol per ton biodiesel produced), which is an oxygenated hydrocarbon having a hydroxyl group on each carbon atom [1]. The current disposal method of surplus glycerol from biodiesel production is primarily incineration (at million metric tons scale per year in Europe), which brings significant environmental impact on the biodiesel manufacture and the biofuel supply chain. Therefore, finding suitable alternative solutions to capitalise on the surplus glycerol can not only mitigate the associated environmental impact (due to incineration) but also increase the economic viability of biodiesel manufacture. To answer this challenge, various catalytic routes, such as reforming, oxidation, dehydration and esterification, have been proposed to transform glycerol into value-added chemicals and fuels [2].

Among the proposed catalytic transformations, the catalytic reforming of glycerol is attractive due to the production of $\mathrm{H}_{2}$ which, as the zero-emission fuel, can be used in fuel cells and internal combustion engines. The 
major technologies of $\mathrm{H}_{2}$ production via glycerol conversion are steam reforming (SR) [3], partial oxidation reforming (POXR) [4] and oxidative steam reforming (OSR) [5]. Although POXR and OSR processes have the advantage of fast start-up time due to the exothermic nature of the oxidation reactions, the steam reforming of glycerol (SRG) is relatively more attractive. Theoretically, SR produces seven moles of $\mathrm{H}_{2}$ for every mole of glycerol fed into the reaction. Conversely, (i) in conventional SR of non-renewable sources, such as methane $\left(\mathrm{CH}_{4}\right)$, only three moles of $\mathrm{H}_{2}$ is obtained from one mole of $\mathrm{CH}_{4}$ (Eqs. (1) and (2)) and (ii) four and five moles of $\mathrm{H}_{2}$ were extracted via POXR and OSR, respectively (Eqs. (3) and (4)) [5]. More importantly, glycerol can potentially be used as the renewable feed or co-feed to the current industrial processes of conventional steam reforming without the significant change of the relevant infrastructure $[1,6]$.

SRG refers to the reaction between glycerol and water, both as vapours, to produce $\mathrm{H}_{2}$ and $\mathrm{CO}_{2}$, as shown in Eq. (1). However, since glycerol is a carbohydrate, SRG has a relatively more complex reaction network in comparison with SR of hydrocarbons [2]. Reactions during SRG may include steam $\mathrm{CH}_{4}$ reforming (Eq. (2)), thermal decomposition of glycerol into $\mathrm{CO}$ and $\mathrm{H}_{2}$ (Eq. (5)), water-gas shift reaction (WGSR) of converting $\mathrm{CO}$ into $\mathrm{CO}_{2}$ along with $\mathrm{H}_{2}$ (Eq. (6)) and $\mathrm{CO}$ and $\mathrm{CO}_{2}$ methanation reactions as shown in Eqs. 7(a) and 7(b), respectively. Subsequently, the process is accompanied by $\mathrm{CH}_{4}$ dry reforming (Eq. (8)), and other side reactions which lead to carbon deposition, as shown in Eqs. (9-12) [7]. Glycerol decomposition and WGSR are primary reactions in SRG. Due to the highly endothermic nature of thermal decomposition of glycerol (Eq. (5)), the overall process of SRG is endothermic (Eq. (1)). Consequently, as shown in Eq. (1), high temperatures, atmospheric pressure and high steam-to-glycerol reactant ratios can theoretically benefit the yield of $\mathrm{H}_{2}$. However, the simultaneous occurrence of multiple side reactions in SRG, with different thermodynamic natures, results in thermal inefficiencies of the system, and hence the by-products generation, affecting the selectivity and overall yield of $\mathrm{H}_{2}$. Generally, although high temperatures are beneficial to $\mathrm{H}_{2}$ production, they increase the operating cost and energy consumption, while lower temperatures promote the production of $\mathrm{CH}_{4}$ with reduced selectivity to $\mathrm{H}_{2}$. Therefore, efficient catalysts which would be selective for $\mathrm{H}_{2}$ production at relatively on reaction temperatures are highly desired for the rational and sustainable utilisation of glycerol.

$\mathrm{H}_{2}$ production via SRG is beneficial from the point of view of using a by-product from the biofuel manufacture for value-added clean fuel. However, as stated above, the reaction network of SRG is complex with the simultaneous production of several undesirable by-products, affecting the $\mathrm{H}_{2}$ purity with significant cost implications (i.e., uneconomic multiple separation and purification processes are needed for $\mathrm{H}_{2}$ purification). In addition, yield of $\mathrm{H}_{2}$ also depends strongly on different process variables such as temperature, pressure and steam-to-glycerol feed molar ratio (SGFR). Therefore, to make $\mathrm{H}_{2}$ production via $\mathrm{SRG}$ viable and selective, in addition to the catalyst design for improving the selectivity to $\mathrm{H}_{2}$, research into the exploration of optimum operation windows to suppress the formation of by-products is also necessary.

SR reactions:

$$
\begin{gathered}
\mathrm{C}_{3} \mathrm{H}_{8} \mathrm{O}_{3}+3 \mathrm{H}_{2} \mathrm{O} \rightarrow 3 \mathrm{CO}_{2}+7 \mathrm{H}_{2} \\
\Delta H_{298}=127.7 \mathrm{~kJ} \cdot \mathrm{mol}^{-1} \\
\mathrm{CH}_{4}+\mathrm{H}_{2} \mathrm{O} \leftrightarrow \mathrm{CO}_{2}+3 \mathrm{H} \Delta H_{298}=205.8 \mathrm{~kJ} \cdot \mathrm{mol}^{-1} .
\end{gathered}
$$

Partial oxidation reaction:

$$
\begin{gathered}
\mathrm{C}_{3} \mathrm{H}_{8} \mathrm{O}_{3}+1.5 \mathrm{O}_{2} \rightarrow 3 \mathrm{CO}_{2}+4 \mathrm{H}_{2} \\
\Delta H_{298}=-603.0 \mathrm{~kJ} \cdot \mathrm{mol}^{-1}, \\
\mathrm{C}_{3} \mathrm{H}_{8} \mathrm{O}_{3}+\mathrm{O}_{2}+\mathrm{H}_{2} \mathrm{O} \rightarrow 3 \mathrm{CO}_{2}+5 \mathrm{H}_{2} \\
\Delta H_{298}=-269.0 \mathrm{~kJ} \cdot \mathrm{mol}^{-1} .
\end{gathered}
$$

Decomposition reaction:

$$
\mathrm{C}_{3} \mathrm{H}_{8} \mathrm{O}_{3} \rightarrow \mathrm{CO}+4 \mathrm{H}_{2} \Delta H_{298}=251.2 \mathrm{~kJ} \cdot \mathrm{mol}^{-1} \text {. }
$$

Water gas shift reaction:

$$
\mathrm{CO}+\mathrm{H}_{2} \mathrm{O} \leftrightarrow \mathrm{CO}_{2}+\mathrm{H}_{2} \Delta H_{298}=-41.2 \mathrm{~kJ} \cdot \mathrm{mol}^{-1} \text {. }
$$

Methanation reactions:

$\mathrm{CO}+3 \mathrm{H}_{2} \leftrightarrow \mathrm{CH}_{4}+\mathrm{H}_{2} \mathrm{O} \Delta H_{298}=-205.8 \mathrm{~kJ} \cdot \mathrm{mol}^{-1}$,

$\mathrm{CO}_{2}+4 \mathrm{H}_{2} \leftrightarrow \mathrm{CH}_{4}+2 \mathrm{H}_{2} \mathrm{O} \Delta H_{298}=-164.6 \mathrm{~kJ} \cdot \mathrm{mol}^{-1}$.

$\mathrm{CH}_{4}$ dry reforming reaction:

$\mathrm{CO}_{2}+\mathrm{CH}_{4} \leftrightarrow 2 \mathrm{CO}+2 \mathrm{H}_{2} \Delta H_{298}=247.0 \mathrm{~kJ} \cdot \mathrm{mol}^{-1}$.

Coke formation reactions:

$$
\begin{gathered}
\mathrm{CH}_{4} \leftrightarrow 2 \mathrm{H}_{2}+\mathrm{C} \Delta H_{298}=74.5 \mathrm{~kJ} \cdot \mathrm{mol}^{-1}, \\
2 \mathrm{CO} \leftrightarrow \mathrm{CO}_{2}+\mathrm{C} \Delta H_{298}=-172.4 \mathrm{~kJ} \cdot \mathrm{mol}^{-1}, \\
\mathrm{CO}+\mathrm{H}_{2} \leftrightarrow \mathrm{H}_{2} \mathrm{O}+\mathrm{C} \Delta H_{298}=-131.3 \mathrm{~kJ} \cdot \mathrm{mol}^{-1}, \\
\mathrm{CO}_{2}+2 \mathrm{H}_{2} \leftrightarrow 2 \mathrm{H}_{2} \mathrm{O}+\mathrm{C} \Delta H_{298}=-90.1 \mathrm{~kJ} \cdot \mathrm{mol}^{-1} .
\end{gathered}
$$

The primary objective of SRG is to produce renewable 
hydrogen, however, the selectivity to $\mathrm{H}_{2}$ of SRG remains challenging due to the multiple side reactions existed in the gas phase. Also, it is challenging to extract the comprehensive information of the complex chemistry in SRG via experimental studies. The recent reviews provide an overview of SRG chemistry and catalysts development for SRG, as well as the theoretical feasibility and its potential application for value-added chemicals and $\mathrm{H}_{2}$ production [8-10]. In addition, new reactor systems such as membrane reactor (MR), sorption-enhanced reactor and sorption-enhanced membrane reactor are proposed to achieved high-purity $\mathrm{H}_{2}$ and remove $\mathrm{CO}_{2}$ from the reaction zone by means of a $\mathrm{H}_{2}$ selective membrane and $\mathrm{CO}_{2}$ selective sorbent [11-13]. The use of such alternative technologies, such as MRs can be beneficial regarding the production of high-purity $\mathrm{H}_{2}$ from SRG [9]. In particular, MRs can be operated at relatively low temperatures with comparable or improved glycerol conversions in comparison with conventional reactors (CR). For example, Lin et al. [13] have investigated the SRG reaction over $\mathrm{Ni} / \mathrm{CeO}_{2} / \mathrm{Al}_{2} \mathrm{O}_{3}$ catalyst in $\mathrm{CR}$ and $\mathrm{MR}$ operated at $723 \mathrm{~K}-1073 \mathrm{~K}$ and $673 \mathrm{~K}-723 \mathrm{~K}$, respectively. It was found that the $\mathrm{Pd}-\mathrm{Ag}$ membrane can effectively purify $\mathrm{H}_{2}$ from the reaction side and subsequently enhance the reaction rate in a single compact unit. Similarly, SRG with the improved performance regarding glycerol conversion $(\sim 60 \%)$ and a CO-free $\mathrm{H}_{2}$ recovery $(\sim 60 \%)$ was also reported by Iulianelli et al. [14] with a Pd-Ag MR. However, it is worth mentioning that MRs require relatively high pressures to operate which do not favor the thermodynamics of SRG. And research on catalyst development, thermodynamics and kinetics, as well as the optimisation of operational parameters of SRG is still needed for developing practical SRG at large scales. Although thermodynamic analysis does not include the effect of catalysts, chemical equilibrium analysis is necessary and imperative to obtain the information on operational windows which are suitable for $\mathrm{H}_{2}$ selective SRG. Thermodynamic equilibrium analysis is commonly used to estimate the products composition of reforming processes and identify operating windows for target reactions and coke formation [15]. The complex chemistry and the effect of operational conditions on the equilibrium composition are usually solved using the combined stoichiometric thermodynamic methods, in which the system is described by a set of stoichiometrically independent reactions chosen arbitrarily by the modeller [16]. Conversely, in a non-stoichiometric method, the specification of defined reactions in a system is not necessary since the equilibrium composition of a reacting system is established by minimising the Gibbs free energy for the defined species in the system. This is advantageous over the stoichiometric-thermodynamic method since the knowledge of independent chemical reactions in the complex system and the values of corresponding equilibrium constants are not required in simulation.

Thermodynamic studies of SRG were performed to understand the distribution of $\mathrm{H}_{2}, \mathrm{CH}_{4}, \mathrm{CO}, \mathrm{CO}_{2}$, solid $\mathrm{C}$, $\mathrm{H}_{2} \mathrm{O}$ and unreacted $\mathrm{C}_{3} \mathrm{H}_{8} \mathrm{O}_{3}$ [4,5,17-20]. Adhikari et al. showed that $\mathrm{H}_{2}$ production from $\mathrm{SRG}$ was favoured at $>898 \mathrm{~K}$ and a molar ratio of water to glycerol of 9:1, in which $\mathrm{CH}_{4}$ production is surepressed and carbon formation is thermodynamically inhibited [17]. Li et al. studied the thermodynamics of SR of oxygenate fuels such as methanol, ethanol, ethylene glycol and glycerol, and optimal temperature window for $\mathrm{H}_{2}$ production from SRG was estimated at 873-973 K [20]. It was also found that, under the optimal conditions, SRG is limited by equilibrium regarding $\mathrm{H}_{2}$ yield. Considering the system pressure of SRG, relatively low pressures are beneficial to $\mathrm{H}_{2}$ production under equilibrium conditions (whilst higher pressures are favourable for $\mathrm{CH}_{4}$ formation instead) [21]. Since negative pressure ( $<$ the atmospheric pressure) operation is challenging in practice, the use of inert carrier gas, such as $\mathrm{N}_{2}$ which is commonly used in the experimental studies of SRG, to reduce the partial pressure of gaseous species could be a possible alternative for improving $\mathrm{H}_{2}$ production from SRG. However, this aspect has been overlooked by previous studies.

Herein, thermodynamic modelling of SRG was performed, based on a direct Gibbs free energy minimisation method using CHEMCAD v.6.5 software, for selective $\mathrm{H}_{2}$ production at various conditions. Attention was focused on the calculation of equilibrium compositions for SRG considering comprehensive side reactions at different operational regime of temperatures, pressures, SGFR, feeding reactant to inert gas ratio. The reforming performance of SRG was assessed with respect to the glycerol conversion, selectivity to $\mathrm{H}_{2}$ and $\mathrm{H}_{2}$ molar fraction and yield. More importantly, simulation practice in this work explores the relevant operating windows and the effect of using inert carrier gas for minimising carbon formation and enhancing $\mathrm{H}_{2}$ production in $\mathrm{SRG}$.

\section{Experimental}

Thermodynamic equilibrium analysis of SRG was carried out to evaluate the feasibility of occurrence of relevant reactions such as SR, decomposition and coke formation reaction in SRG (as in Eqs. (1), (2) and (5-12)) by calculating equilibrium constants $\left(K_{\text {eq }}\right)$ and determine the equilibrium compositions under different conditions, respectively. The values of $\Delta H_{\mathrm{f}}^{0}$ and $\Delta G_{\mathrm{f}}{ }^{0}$ for each of the component species were adopted from the literature [22]. The reference temperature of $298 \mathrm{~K}$ was used and $K_{\text {eq }}$ in form of $\ln K_{\text {eq }}$ was evaluated at temperatures of $600 \mathrm{~K}$ to $1100 \mathrm{~K}$ with $50 \mathrm{~K}$ increment. The Gibbs free energy change of each reaction $\left(\Delta G_{\mathrm{r}}^{0}\right)$ was calculated at different temperatures using Eq. (13). 


$$
\begin{gathered}
\Delta G_{\mathrm{r}}^{0}=\sum_{i} \gamma_{i} \Delta G_{f_{i}}^{0}, \\
K^{\prime}=\exp \left(\frac{-\Delta G_{\mathrm{r}}^{0}}{\mathrm{R} T}\right), \\
\ln \frac{K}{K^{\prime}}=-\frac{\Delta H_{\mathrm{r}}^{0}}{\mathrm{R}}\left(\frac{1}{T}-\frac{1}{T^{\prime}}\right), \\
\ln K=-\frac{\Delta H_{\mathrm{r}}^{0}}{\mathrm{R}}\left(\frac{1}{T}-\frac{1}{T^{\prime}}\right)+\ln K^{\prime},
\end{gathered}
$$

where $\gamma_{i}$ is the stoichiometric coefficient of species $i$ and $\Delta G_{i}^{0}$ is the Gibbs free energy of the formation of species $i$. The $\Delta H_{\mathrm{r}}^{0}$ is given as the standard enthalpy of the reaction, $T^{\prime}$ is the reference temperature, $T$ is the reaction temperature, and $K^{\prime}$ is the equilibrium constant at the reference temperature. Additionally, the equilibrium constant is usually determined by either Eq. (14) or Van't-Hoff Eq. (15) [22]. For each reaction considered, the values of $K_{\text {eq }}$ in form of $\ln K_{\text {eq }}$ were calculated and plotted according to the modified Eq. (16) to predict the values of $\ln K_{\text {eq }}$ as a function of reaction temperature $T$. Key process parameters such as glycerol conversion and hydrogen yield used to assess the process efficiency are defined as in Table 1.

The total Gibbs free energy of a reacting system reaches a minimum value at equilibrium, and the Gibbs energy of a chemical system is a function of temperature, pressure and number of moles of species. If the temperature and pressure of a given system are fixed, its total Gibbs free energy function $\left(G^{t}\right)$ is given by Eq. (17) [18,22].

Table 1 Definition of various parameters used in the analysis of SRG

\begin{tabular}{lrl}
\hline Parameter & Formula \\
\hline Glycerol conversion & $X_{\text {glycerol }}(\%)=\frac{F_{\text {glycerol }}^{\text {in }}-F_{\text {glycerol }}^{\text {out }}}{F_{\text {glycerol }}^{\text {in }}} \times 100$ \\
Hydrogen yield & $Y_{\mathrm{H}_{2}}(\%)=\frac{F_{H_{2}}^{\text {out }}}{7 \times F_{\text {glycerol }}^{\text {in }}} \times 100$ \\
Yield of C-containing product $i$ & $Y_{i}(\%)=\frac{\# c_{F_{i}}^{\text {out }}}{3 \times F_{\text {glycerol }}^{\text {in }}} \times 100$ \\
Molar fraction & $M F=\frac{n_{i}^{\text {out }}}{n_{\text {total }}^{\text {out }}}$ \\
Product selectivity & $S_{i}(\%)=\frac{F_{i}^{\text {out }}}{\sum{ }_{j} F_{j}^{\text {out }}} \times 100$ \\
$\mathrm{CO}_{2}$ ratio & $\frac{\mathrm{CO}_{2}}{\mathrm{CO}_{x}}=\frac{F_{\mathrm{CO}}^{\text {out }}}{F_{\mathrm{CO}}+F_{\mathrm{CO}}^{\text {out }}}$ \\
\hline
\end{tabular}

Note: where $F$ refers to the relevant molar flowrate (mole/h); superscripts in and out represent the inflow and outflow of the reactor. $X$ refers to the glycerol conversion calculated based on the glycerol molar inflow and outflow of the reactor. $\# C$ represents the number of carbon atoms in particular specie. $M F$ refers to the molar fraction calculated based on the ratio of an individual product to the total molar flow of all products leaving the reactor. Product selectivity is calculated based on product distribution, while $F_{j}$ excludes unconverted glycerol, water and nitrogen. $\mathrm{CO}_{2} / \mathrm{CO}_{x}$ is the molar ratio of $\mathrm{CO}_{2}$ to the sum of $\mathrm{CO}_{2}$ and $\mathrm{CO}$

$$
\begin{aligned}
& G^{\mathrm{t}}=\sum_{i=1}^{N} n_{i} G_{i}=\sum_{i=1}^{N} n_{i} \mu_{i} \\
& =\sum_{i=1}^{N} n_{i} G_{i}^{0}+\mathrm{R} T \sum_{i=1}^{N} n_{i} \ln \frac{f_{i}}{f_{i}^{0}}, \\
& \Delta G_{f_{i}}^{0}+\mathrm{R} T \ln \frac{y_{i} \phi_{i} P}{P^{0}}+\sum_{k} \lambda_{k} a_{i k}=0 \\
& \sum_{i=1}^{N} n_{i}\left(\Delta G_{f_{i}}^{0}+\mathrm{R} T \ln \frac{y_{i} \phi_{i} P}{P^{0}}+\sum_{k} \lambda_{k} a_{i k}\right)=0 \\
& \sum_{i=1}^{N} n_{i} a_{i k}=A_{k}(\text { for } k=1,2,3, \ldots, M), \\
& G_{C(g)}=G_{C(s)}=\Delta G_{f C(s)}^{0}=0, \\
& \sum_{i=1}^{N-1} n_{i}\left(\Delta G_{f_{i}}^{0}+\mathrm{R} T \ln \frac{y_{i} \phi_{i} P}{P^{0}}+\sum_{k} \lambda_{k} a_{i k}\right) \\
& +\left(n_{C} \Delta G_{f C(s)}^{0}\right)=0 .
\end{aligned}
$$

For reaction equilibria in gas phase, $f_{i}=y_{i} \phi_{i} P$, in which $f_{i}$ is the fugacity of species $i, y_{i}$ is the molar fraction of species $i$ and $\phi_{i}$ is the fugacity coefficient of species $i$ in the gaseous phase, respectively. Since the standard state is defined as the pure ideal gas state at atmospheric pressure, $f_{i}^{0}=P^{0}=1.013 \times 10^{5} \mathrm{~Pa}$. Similarly, since $G_{i}{ }^{0}$ is set equal to zero for each chemical element in its standard state, $\Delta G_{i}{ }^{0}$ $=\Delta G_{f i}{ }^{0}$ for each component species is assumed. Therefore, substituting these into Eq. (17), the minimum Gibbs free energy of each gaseous species and that of the total system can be expressed by Eqs. (18) and (19), respectively, with the incorporation of Lagrange multiplier method. However, to find the set of $n_{i}$ that minimise the value of Gibbs free energy at the constant temperature and pressure, the constraint of elemental mass balances, as shown in Eq. (20), must be satisfied. Similarly, when the solid carbon is considered in the reaction system, the Gibbs-free energy of carbon is usually considered using Eq. (21), and the minimisation function of Gibbs free energy of Eq. (22) is obtained by substituting Eq. (17) by Eq. (18) for gaseous species and by Eq. (21) for solid species according to the literature $[19,23] . N-1$ is the number of substances which are present only in the gas phase while carbon is present as the solid species using the same constraint in Eq. (18). The equilibrium compositions for SRG were determined using the Gibbs free energy reactor (GIBS) model in CHEM$\mathrm{CAD}$ by solving heat and mass balances while minimising the free energy of component species produced during 
SRG. According to the equilibrium compositions of SRG, the main possible species are considered; $\mathrm{H}_{2}, \mathrm{CH}_{4}, \mathrm{CO}$, $\mathrm{CO}_{2}, \mathrm{H}_{2} \mathrm{O}, \mathrm{C}_{3} \mathrm{H}_{8} \mathrm{O}_{3}$ and solid carbon. Elements of $\mathrm{C}, \mathrm{H}$ and $\mathrm{O}$ are present in relevant species and are used for elemental mass balance. Furthermore, all species involved were input in the feed stream at a reference temperature of $298 \mathrm{~K}$. In addition, for all simulations, the feed stream was maintained as a gas mixture (presumably by a preheater), and the temperature of the reactants was maintained at $583 \mathrm{~K}$. The isothermal condition was applied to the GIBS reactor in the simulation. The Soave-Redlich-Kwong equation of state was used to calculate the fugacity coefficient of each component in the gas mixture. The physical properties and ideal gas standard Gibbs free energy of formations of all the components are obtained from the pure component library database in CHEMCAD [24]. Similarly, in flowsheeting, reactant species with their respective proportions are identified, and the minimisation is performed to calculate the chemical equilibrium concentrations of the product stream.

\section{Results and discussion}

\subsection{Equilibrium constants of possible reactions}

The equilibrium rate constant of SRG reaction and other relevant possible reactions (as shown in the Electronic Supplementary Material, ESM) were included in thermodynamic analysis to identify the extent of the reactions. This analysis would be helpful to determine whether the reaction proceeds spontaneously (i.e., the reaction has a negative value of $\Delta G_{\mathrm{r}}{ }^{0}$ ) or it is thermodynamically limited (i.e., the reaction has a positive value of $\Delta G_{\mathrm{r}}^{0}$ which requires specific conditions to occur). Conversely, when the value of $\ln K_{\text {eq }}$ (Eq. (16)) is much larger than 1, the reaction equilibrium cannot be shifted by changing the feed ratio of the reactant (for example, decomposition reaction of glycerol, Eq. (5)). But for the value of $\ln K_{\mathrm{eq}}$ close to unity, variation of the feed ratio of the reactants influences the distribution of the products. Furthermore, the larger the values of $\ln K_{\text {eq }}$ (Eq. (16), i.e., the reaction has a negative value of $\Delta G_{i}{ }^{0}$ and its absolute value of $\Delta G_{i}{ }^{0}$ is relatively large), the more likely for the reactions are to occur spontaneously [25]. The equilibrium constants of all feasible reactions in SRG as a function of the process temperature are shown in Fig. 1. One can see that the glycerol reforming and decomposition reaction (Eqs. (1) and (5), which consumes glycerol, Fig. 1(a)) possess the relatively large $\ln K_{\text {eq }}$ values in comparison with other reactions. In a system with multiple reactions, the reactions with comparatively large equilibrium constants determine the product distribution [18]. Accordingly, the simulation predicted that, at atmospheric pressure, $100 \%$ conversion of glycerol was achieved over the range of temperatures and SGFR considered by this work (Fig. S1, cf. ESM), producing mainly $\mathrm{H}_{2}, \mathrm{CO}_{2}$ and $\mathrm{CO}$.

Figure 1(b) shows the competition between various side reactions during SRG. The equilibrium constant of WGSR (Eq. (6)) decreases with an increase of the temperature, suggesting the WGSR reaction is feasible and spontaneous at temperatures of $<1000 \mathrm{~K}$ but limited by the equilibrium at temperatures above $1000 \mathrm{~K}$. The formation of $\mathrm{CH}_{4}$ via $\mathrm{CO} / \mathrm{CO}_{2}$ methanation (Eqs. 7(a) and 7(b)) is exothermic, and therefore is likely to occur at temperatures of $<950 \mathrm{~K}$ with positive values of $\ln K_{\text {eq. }}$. In contrast, the dry reforming (Eq. (8)) and SR of $\mathrm{CH}_{4}$ (Eq. (2)) reactions, which consume $\mathrm{CH}_{4}$, are favoured at high temperatures (i.e., $>950 \mathrm{~K}$ ), as indicated by their $\ln K_{\text {eq }}$ values of $>1$. Accooridngly, in order to suppress the formation of $\mathrm{CH}_{4}$ in SRG, high temperatures of $>950 \mathrm{~K}$ are recommended based on the findings of the simulation, which agree well
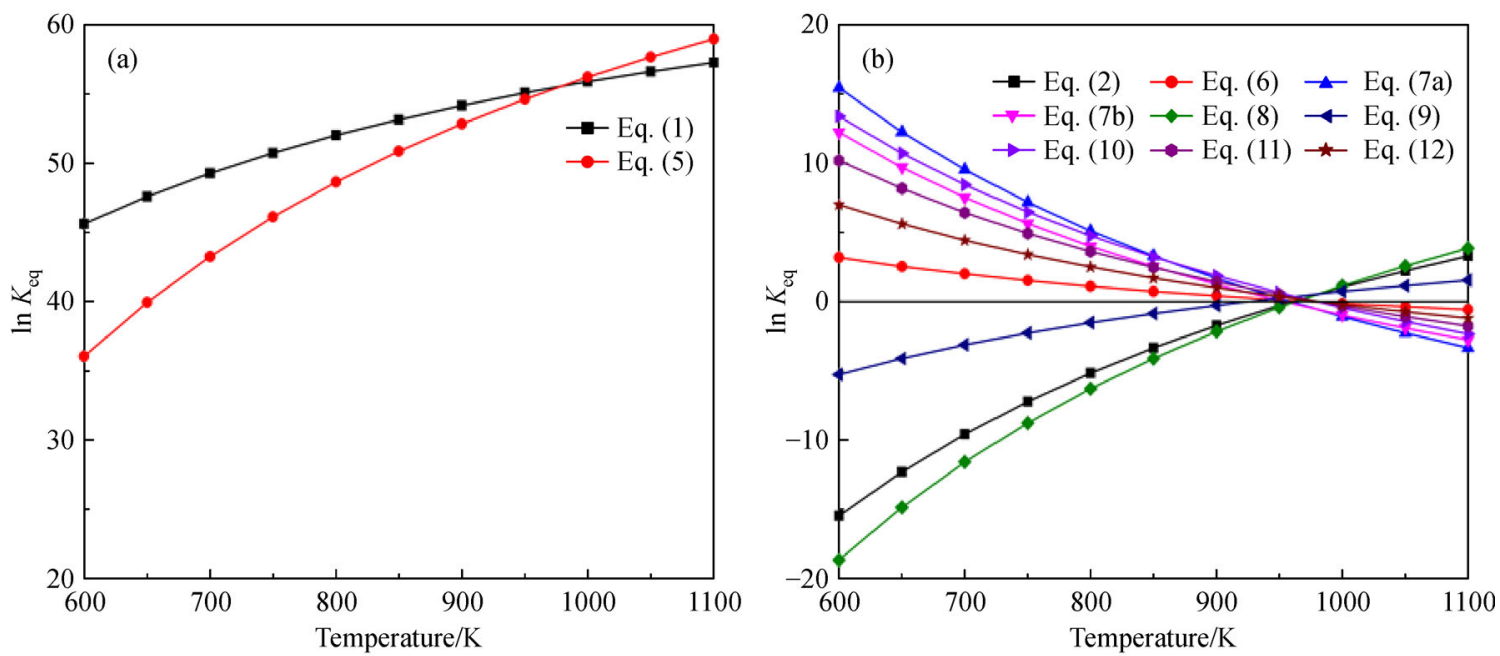

Fig. 1 Equilibrium constants of reactions occurred in SRG as a function of the process temperature as described by (a) Eqs. (1) and (5) and (b) Eqs. (2-12). 
with the previous results [26].

Carbon formation in SRG, may be formed via $\mathrm{CH}_{4}$ decomposition (Eq. (9)), CO disproportionation (Eq. (10)), $\mathrm{CO}$ reduction (Eq. (11)) and $\mathrm{CO}_{2}$ reduction (Eq. (12)), respectively. $\mathrm{CH}_{4}$ decomposition (Eq. (9)) is prone to encourage carbon formation at relatively high temperatures, whereas the reactions of Eqs. (10-12) are likely to generate carbon at low temperatures of $<950 \mathrm{~K}$ and can be influenced by equilibrium limitations at relatively high temperatures. Therefore, to minimise carbon formation from these reactions, SRG at temperature $>950 \mathrm{~K}$ may be benefitial due to the low values of equilibrium constants of the reactions shown in Fig. 1(b). Additionally, reforming reaction at high temperatures may promote the removal of carbon via reverse reactions (Eqs. (10-12)) [25].

\subsection{SGFR on product distribution}

At atmospheric pressure, the effect of operating temperature and SGFR (of the feed) on $\mathrm{H}_{2}$ production at equilibrium was studied (Fig. 2). As shown in Fig. 2(a), The molar fraction of $\mathrm{H}_{2}$ steadily decreases with an increase in SGFR from 3:1 to 10:1 under steam rich condition which is due to the presence of significant amount of unreacted steam in the product stream, diluting the molar fraction of $\mathrm{H}_{2}$, but not necessarily its quantity. This is evidenced by findings presented in Fig. 2(b), showing the absolute yield of hydrogen being produced at different SGFRs as a function of reaction temperature. Steam rich conditions with high SGFR values are beneficial to promote $\mathrm{H}_{2}$ production. Accordingly, under these conditions, optimum temperatures were predicted for each SGFR condition from 3:1 to 10:1. For example, at SGFR $=10: 1$, the optimum range of temperatures for maximising $\mathrm{H}_{2}$ production was estimated to be at $900 \mathrm{~K}-$ $1050 \mathrm{~K}$, being comparable with the experimental data over supported Ni catalysts with $\mathrm{SGFR}=9: 1$ which were measured as at $973 \mathrm{~K}-1023 \mathrm{~K}$ [27]. By increasing the operation temperature beyond $1050 \mathrm{~K}$, the temperature shows the adverse effect on the yield of hydrogen due to
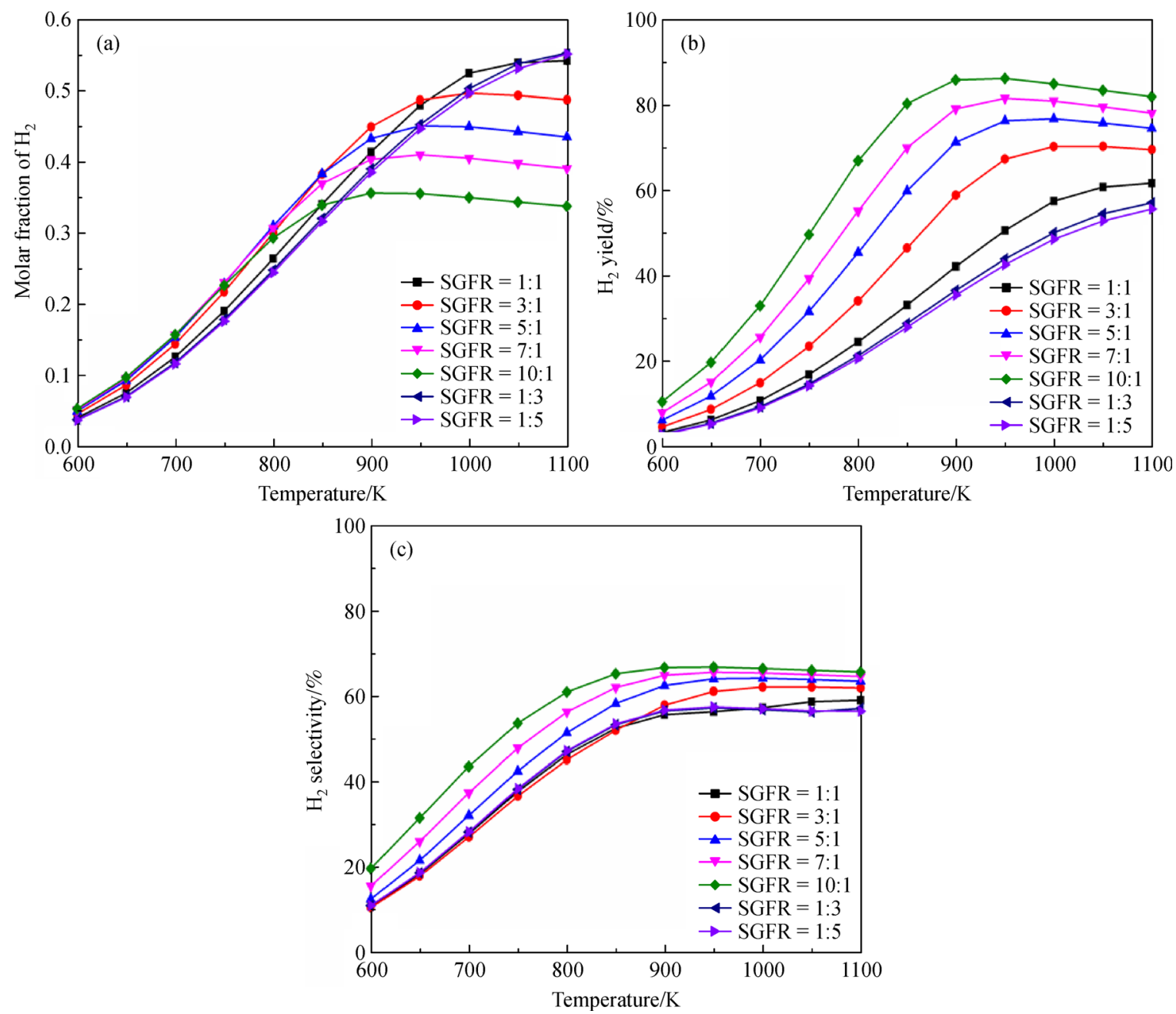

Fig. 2 Thermodynamic equilibrium analysis of SRG at atmospheric pressure: effect of temperature and SGFR on (a) molar fraction of $\mathrm{H}_{2}$; (b) $\mathrm{H}_{2}$ yield; (c) $\mathrm{H}_{2}$ selectivity. 
the reverse WGSR which forms $\mathrm{CO}$ and $\mathrm{H}_{2} \mathrm{O}$. This is confirmed by data on $\mathrm{CO}$ formation, that is, $\mathrm{CO}$ yield is promoted at high temperatures (to be discussed later). Under steam deficit conditions (SGFR = 1:1, 1:3 and 1:5), at various temperatures, SGFR shows insignificant effect on the molar fraction and yield of hydrogen. However, the hydrogenation reactions ( of $\left.\mathrm{CO} / \mathrm{CO}_{2}\right)$ are favourable at the specified SGFR. For example, at $\mathrm{SGFR}=1: 5$, the formation of carbon is thermodynamically feasible especially at temperatures $<1050 \mathrm{~K}$ (to be discussed in detail later), consuming the hydrogen produced. Selectivity to hydrogen (product moles of hydrogen/sum of moles of all products except water) is shown Fig. 2(c). In general, with SGFR above 5:1, SRG shows relatively high selectivity to $\mathrm{H}_{2}$ over the range of temperatures under study. This can be ascribed to glycerol reforming (Eq. (1)) which is favoured at high SGFR. The selectivity to $\mathrm{H}_{2}$ plateaued at high temperatures of $>900 \mathrm{~K}-1050 \mathrm{~K}$, as well as for the selectivity to $\mathrm{CO}_{2}$ (Fig. S2(a), cf. ESM), suggesting the consumption of $\mathrm{H}_{2}$ and $\mathrm{CO}_{2}$ via reverse WGSR (Eq. (6)) and reverse methanation reaction (Eq. 7(a)). This is also confirmed by the selectivity to $\mathrm{CO}$ and $\mathrm{CH}_{4}$ over the range of temperatures considered (Figs. S2(b) and S2(c), cf. ESM), which will be discussed later.

SR processes target the production of syngas $\left(\mathrm{H}_{2}+\mathrm{CO}\right)$. However, $\mathrm{CH}_{4}$ is also a common product of the conventional reforming process, which is not a desirable product in SRG due to side reactions which consume $\mathrm{H}_{2}$ and carbon atoms in the product stream. Figure 3 depicts the molar fraction (Fig. 3(a)) and yield of $\mathrm{CH}_{4}$ (Fig. 3(b)) as a function of temperature and SGFR at atmospheric pressure. Under all conditions investigated, the formation of $\mathrm{CH}_{4}$ is obviously suppressed by an increase in reaction temperature. At relatively low temperatures, methanation reactions (Eqs.7(a) and 7(b)) are very likely to dominate, and hence the improved production of $\mathrm{CH}_{4}$, being consistent with the literature [28]. Temperature variation changes the reaction thermodynamics, being able to either generate the products spontaneously or limit the reactions thermodynamically. Under steam rich conditions, high SGFR values can suppress the formation of $\mathrm{CH}_{4}$. With the SGFR $>7: 1$ and $T>950 \mathrm{~K}, \mathrm{CH}_{4}$ yields can be minimised to a large extent, as shown in Fig. 3(b). This can be due to the steam $\mathrm{CH}_{4}$ reforming reactions of Eq. (2) (the steam $\mathrm{CH}_{4}$ reforming is favoured at high temperatures) and reverse methanation reaction (Eq. 7(b)). Under steam deficit conditions, SGFR again shows insignificant effect on the yield of $\mathrm{CH}_{4}$. The unfavourable formation of $\mathrm{CH}_{4}$ under steam deficit conditions could be due to the thermal decomposition of $\mathrm{CH}_{4}$ via Eq. (9), which is feasible at temperatures higher than $973 \mathrm{~K} \mathrm{[29].}$

Figure 4 shows the influence of temperature and SGFR on equilibrium $\mathrm{CO}$ and $\mathrm{CO}_{2}$ production at atmospheric pressure. Molar fractions of $\mathrm{CO}$ and $\mathrm{CO}_{2}$ produced in $\mathrm{SRG}$ as a function of temperature and SGFR are illustrated in Figs. 5(a) and 5(b), respectively. The molar fraction of CO increases with an increase in the temperature but decreases with an increase in SGFR. Similarly, the molar fraction of $\mathrm{CO}_{2}$ decreases as SGFR rises with temperature above $800 \mathrm{~K}$. However, as shown in Fig. 4(c), the yield of CO is low at a high SGFR $=10: 1$, but it gradually increases with an increase in temperature, suggesting that the production of syngas $\left(\mathrm{CO}\right.$ and $\left.\mathrm{H}_{2}\right)$ is favourable at atmospheric pressure and relatively high temperatures. Again, this can be ascribed to the decomposition of glycerol (Eq. (5)) and steam $\mathrm{CH}_{4}$ reforming (Eq. (2)) reactions which are favourable at high temperatures. Figure 4(d) shows that the yield of $\mathrm{CO}_{2}$ increases with an increase in SGFR and temperatures up to $900 \mathrm{~K}$. Relative high SGFR tends to produce more $\mathrm{CO}_{2}$ which is related to glycerol reforming with steam (Eq. (1)). However, as the production of $\mathrm{CO}_{2}$ attains the maximum at $850 \mathrm{~K}$, it starts to decrease
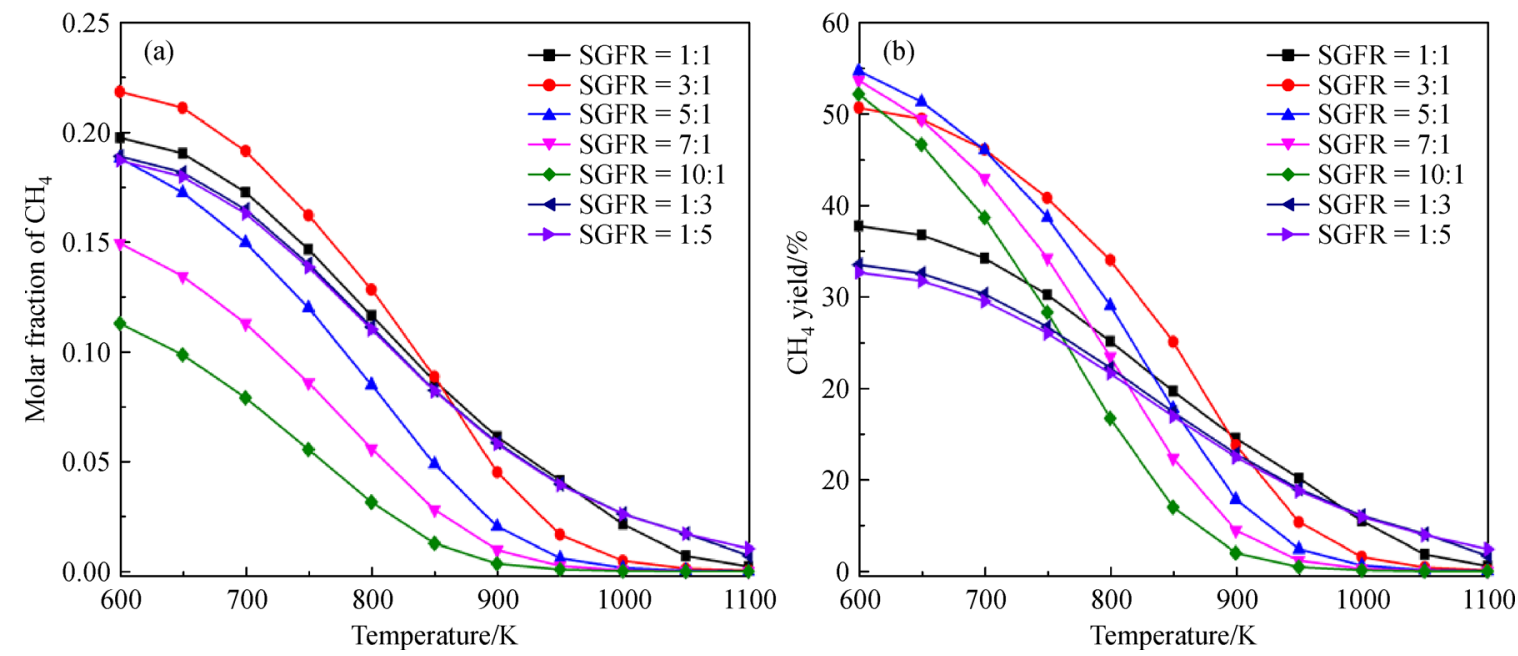

Fig. 3 Thermodynamic equilibrium analysis of SRG at atmospheric pressure: effect of temperature and SGFR on (a) molar fraction of $\mathrm{CH}_{4}$ and (b) $\mathrm{CH}_{4}$ yield. 

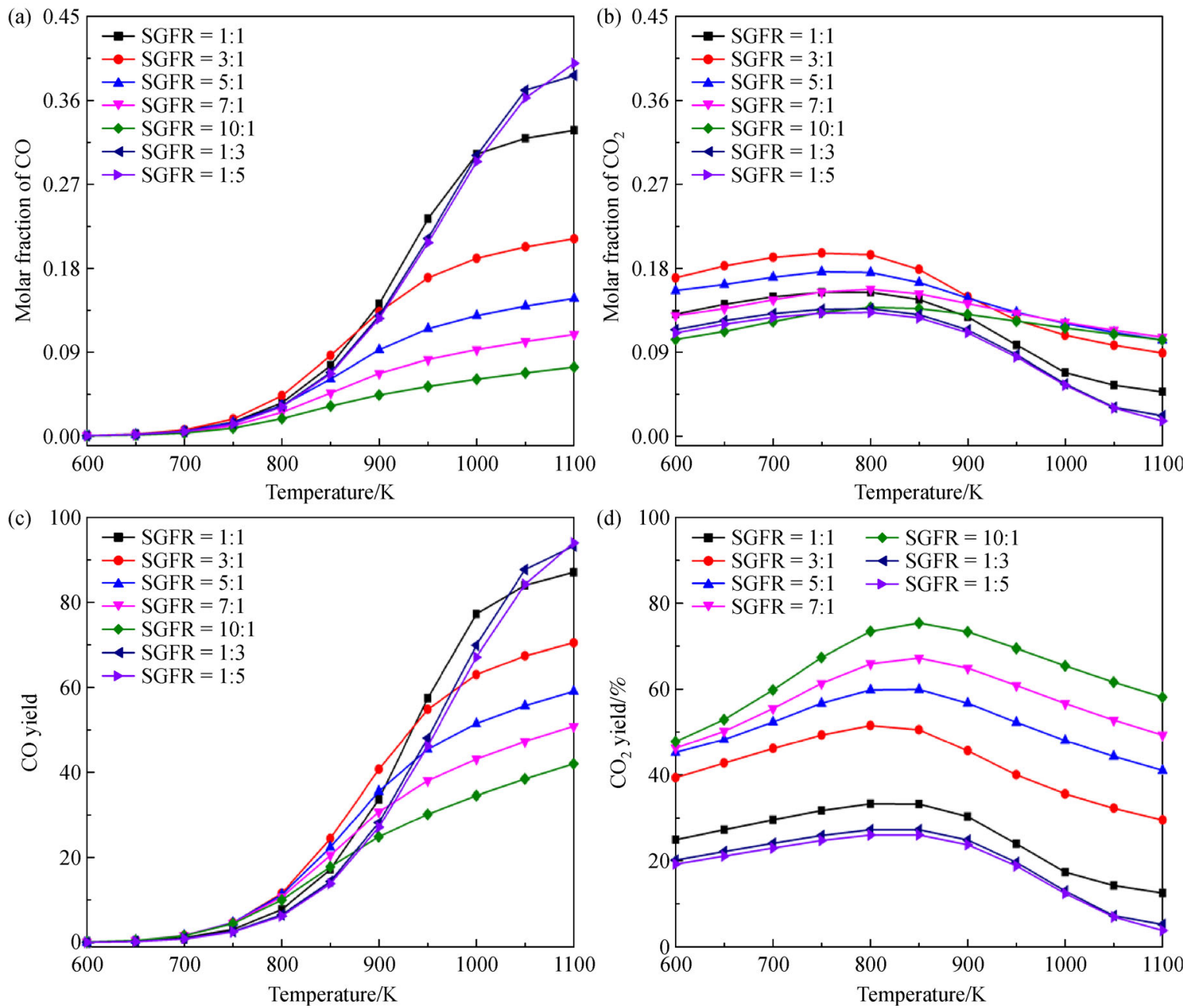

Fig. 4 Thermodynamic equilibrium analysis of SRG at atmospheric pressure: effect of temperature and SGFR on (a) molar fraction of $\mathrm{CO}$; (b) molar fraction of $\mathrm{CO}_{2}$; (c) $\mathrm{CO}$ yield; (d) $\mathrm{CO}_{2}$ yield.

afterwards due to dry reforming of $\mathrm{CH}_{4}$ with $\mathrm{CO}_{2}$ to improve the production of syngas (Eq. (8)). On the other hand, oxygenated carbons occurs in the form of $\mathrm{CO}$ and $\mathrm{CO}_{2}$ products obtained from $\mathrm{SRG}$, which could potentially lead to coke formation. The formation of $\mathrm{CO}_{2}$ and $\mathrm{CO}$ are favoured via Eqs. (1) and (5), respectively. In this study, we have evaluated $\mathrm{CO}_{2}$ distribution using the $\mathrm{CO}_{2} / \mathrm{CO}_{x}$ ratio under different reaction conditions of temperature and SGFR (at atmospheric pressure). For equimolar feed, (for example SGFR $=1: 1$ ), nearly equal molar amounts of $\mathrm{CO}$ and $\mathrm{CO}_{2}$ are predicted at $900 \mathrm{~K}$ as shown in Fig. 5. Under the steam rich conditions, the production of $\mathrm{CO}_{2}$ is favoured. This is due to the fact that the SRG reaction, which produces $\mathrm{CO}_{2}$, is favoured by increasing SGFR of the feed. Under the steam deficit conditions, the variation of SGFR has insignificant effect on the $\mathrm{CO}_{2} / \mathrm{CO}_{x}$ ratio.

Carbon formation/deposition is undesirable in SRG, especially under the consideration of the possibility of employing catalysts to increase the efficiency of SRG for $\mathrm{H}_{2}$ production, because carbon deposition can deactivate

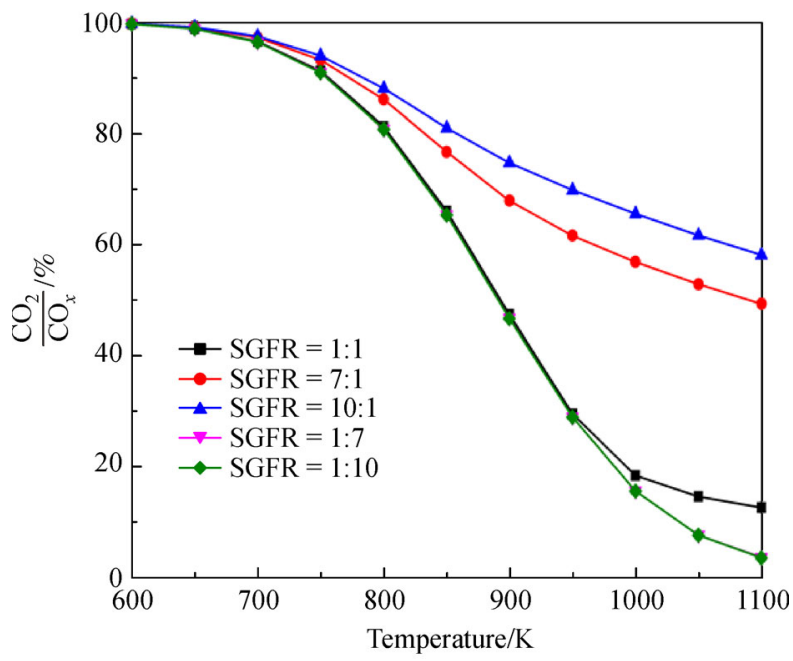

Fig. 5 Effect of temperature and SGFR on the distribution of $\mathrm{CO}_{2} / \mathrm{CO}_{x}$ in $\mathrm{SRG}$ at atmospheric pressure. 
the catalyst over the course of SRG. Therefore, conditions with respect to carbon formation are investigated in this work by equilibrium thermodynamic analysis. Solid carbon formation could be the consequence of the side reactions specified by Eqs. (9-12) due to the decomposition of $\mathrm{CH}_{4}$ and $\mathrm{CO}$ and the reduction of $\mathrm{CO}$ and $\mathrm{CO}_{2}$. However, these reactions can be easily influenced by changing the operational parameters due to their low values of equilibrium constants at $700 \mathrm{~K}-1000 \mathrm{~K}$. SGFR of the feed is the key parameter to determine the $\mathrm{H}_{2}$ production and possibility of carbon formation under reforming conditions [19]. In reforming of alcohols, the production of $\mathrm{CO}$ and $\mathrm{CO}_{2}$ could potentially lead to carbon formation. The molar fraction and yield of carbon at different temperatures and SGFR are shown in Fig. 6. Carbon formation can be inhibited to a large extent when high SGFR values of $>5: 1$ is used, being consistent with the experimental results measured using supported $\mathrm{Ru}$ catalysts [30,31]. Thermodynamic equilibrium shows that at SGFR of $>5: 1$, the molar fraction of carbon is insignificant, suppressing carbon deposition to a large extent within the entire range of temperatures studied. The formation of carbon is also a function of temperature, by increasing the temperature from $800 \mathrm{~K}$ to $950 \mathrm{~K}$, the molar fraction of $\mathrm{C}$ is estimated to decrease from 0.15 and 0.034 to 0 for SGFR of $1: 1$ and 3:1, respectively. Therefore, at relatively high SGFR, an increase in the availability of steam favours the reverse methanation reaction due to the equilibrium shift to the opposite direction which results in the improved $\mathrm{H}_{2}$ production. Conversely, in steam deficit regions, it is found that glycerol molar composition values of $>1: 1$ increases the chance of carbon deposition. As discussed previously, the relatively high yields of $\mathrm{H}_{2}$ are feasible at SGFR values of $>3: 1$. Therefore, carbon-free region can be identified and, theoretically, achieved during SRG at high SGFRs, favouring both $\mathrm{H}_{2}$ production and the suppression of carbon formation. Under steam rich conditions, the selectivity to $\mathrm{H}_{2}, \mathrm{CO}$ and $\mathrm{CO}_{2}$, can be much higher than that to $\mathrm{CH}_{4}$ and $\mathrm{C}$ (Figs. S2(c) and S2(d), cf. ESM).

\subsection{Effect of temperature on glycerol conversion at atmospheric pressure and SGFR of 10:1}

Based on the analysis and discussion above, we identified the condition of atmospheric pressure and SGFR of 10:1 as the optimum condition for SRG, which was further analysised in detail. Figure 7 shows the simulated results of glycerol conversion, selectivity and yield of the main gaseous products under thermodynamic equilibria at different temperatures. It can be seen that the conversion of glycerol is not thermodynamically limited over the range of temperatures investigated in this study. Since glycerol is the limiting reactant in the overall reaction of SRG, the excess steam was further consumed due to the equilibrium limitation which triggered the reverse methanation reaction at relatively high temperatures. However, methanation reaction is an exothermic reaction which is favoured predominantly at low temperatures of $<900 \mathrm{~K}$. This agrees well with the finding presented in Fig. 1. The selectivity results obtained with respect to the formation of $\mathrm{H}_{2}, \mathrm{CO}_{2}, \mathrm{CO}$ and $\mathrm{CH}_{4}$ in the gas phase is compared based on the product distribution from SRG. The selectivity to $\mathrm{H}_{2}$ and $\mathrm{CO}$ increases with an increase in temperature, whereas the selectivity to $\mathrm{CO}_{2}$ decreases. As shown in Fig. 7, it can be seen that $\mathrm{SR}$ of $\mathrm{CH}_{4}$ to $\mathrm{CO}_{2}$ and $\mathrm{H}_{2}$ is favoured, and consequently, the yield of $\mathrm{CH}_{4}$ in the product stream decreases at elevated temperatures (Fig. 3(b)). However, at $900 \mathrm{~K}-1000 \mathrm{~K}$, reverse WGSR (of $\mathrm{CO}_{2}$ with $\mathrm{H}_{2}$ to produce $\mathrm{CO}$ and $\mathrm{H}_{2} \mathrm{O}$ ) is favoured, leading to an increase of the selectivity to $\mathrm{CO}$ (Fig. 8).
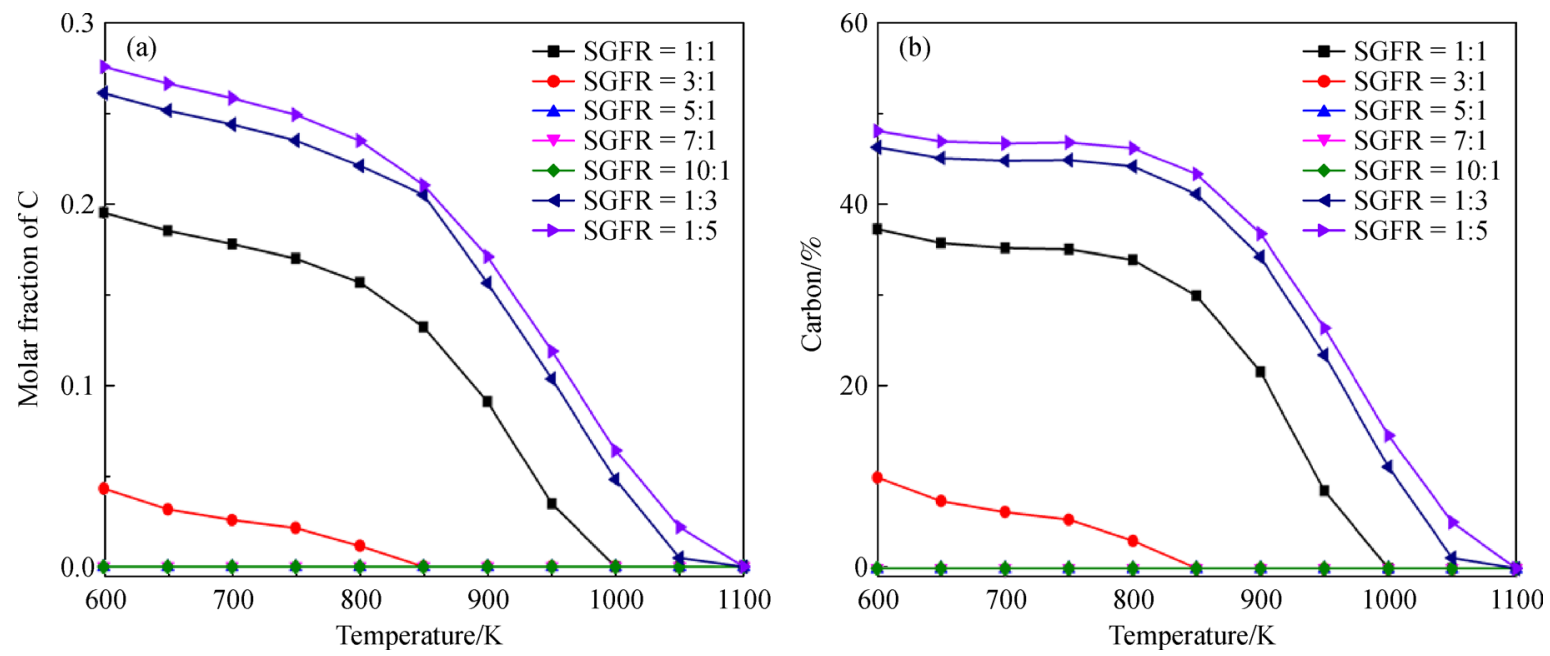

Fig. 6 Thermodynamic equilibrium analysis of SRG at atmospheric pressure: effect of temperature and SGFR on (a) molar fraction of carbon and (b) carbon yield. 


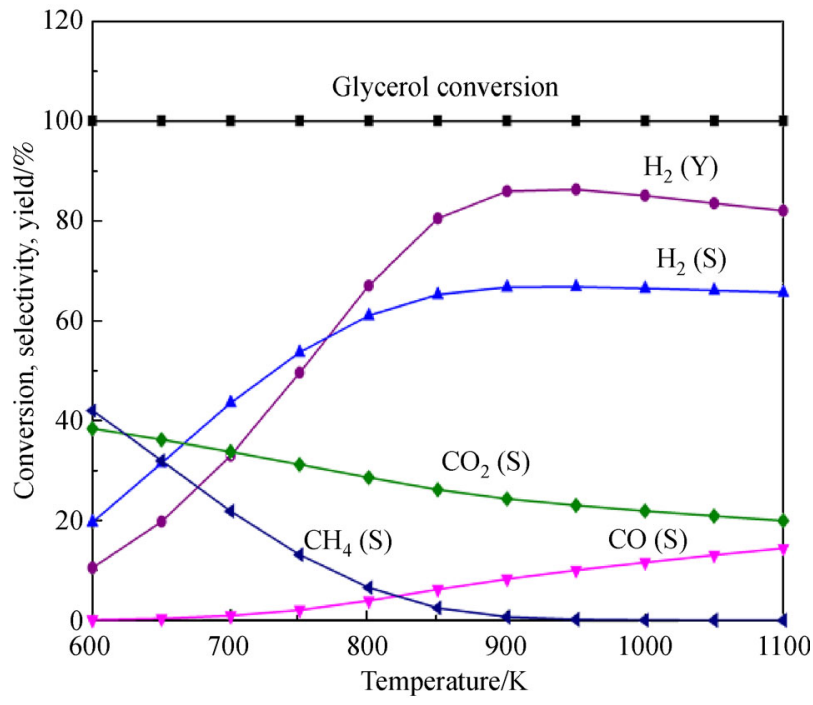

Fig. 7 Product distribution from SRG as a fucntions of reaction temperatures (at atmospheric pressure, $\mathrm{SGFR}=10: 1$ ).

\subsection{Effect of feed dilution using inert gas on hydrogen yield}

The effect of dilution of the feed using inert gas in $\mathrm{H}_{2}$ production from SRG at equilibrium is analysed. $\mathrm{N}_{2}$ is use as an inert gas in SRG for $\mathrm{H}_{2}$ production. The inert gas does not directly get involved in the generation of $\mathrm{H}_{2}$. However, the presence of inert $\mathrm{N}_{2}$ decreases the partial pressure of the reactants, and hence shifting the equilibrium. According to the Le Chatelier's principle, if a chemical system at equilibrium experiences a change in concentration, temperature, volume or partial pressure, the equilibrium shifts to counteract the imposed change. When an inert gas is introduced into the feed into SRG at a constant pressure, the partial pressure of reactive gases decreasees (due to the dilution effect), and hence resulting

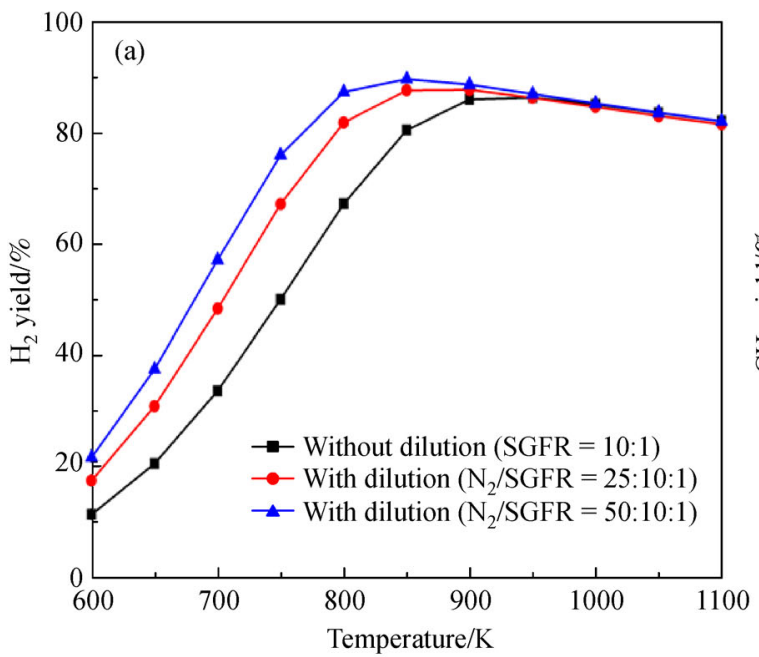

in a shift towards the direction with a relatively large number of moles of gaseous products [22]. Figure 8 shows the effect of feed dilution with $\mathrm{N}_{2}$ on $\mathrm{H}_{2}$ production from $\mathrm{SRG}$ at equilibrium. The introduction of $\mathrm{N}_{2}$ as a carrier gas increases the equilibrium yield of $\mathrm{H}_{2}$ at relatively low temperatures $(<1000 \mathrm{~K})$, but being less significant at high temperatures. The presence of inert $\mathrm{N}_{2}$ decreases the partial pressure of the reactants, and hence shifting the equilibrium. Using Eq. (1) as an example, by reducing the partial pressure of the reactants, $\mathrm{H}_{2}$ production in the SRG system is improved. As discussed previously, the maximum amount of $\mathrm{H}_{2}$ yield is obtained at SGFR $=10: 1$ and temperatures between $900 \mathrm{~K}$ and $1050 \mathrm{~K}$ (Fig. 2(b)). However, when inert gas is considered at the specified ratio (25:10:1), the amount of $\mathrm{H}_{2}$ production increases, and the maximum yield of hydrogen was obtained at temperatures between $800 \mathrm{~K}$ and $1050 \mathrm{~K}$ at shown in Fig. 8(a). Furthermore, as the inert gas dilution ratio increases to 50:10:1, a similar trend of $\mathrm{H}_{2}$ production was obtained (Fig. 8(a)). In general, an increase in the dilution ratio from 25:10:1 to 50:10:1 enhanced $\mathrm{H}_{2}$ production. Conversly, as shown in Fig. 8(b), $\mathrm{CH}_{4}$ yield decreases in an opposite trend due to reverse methanation reaction (Eq. (7)) with an increase of reaction temperature.

\section{Conclusions}

The thermodynamic equilibrium analysis of SRG for $\mathrm{H}_{2}$ production was performed using Gibbs free energy minimisation method. Specifically, (i) the effect of reaction temperature under steam rich and deficit (by varying SGFR) on the performance of SRG was investigated and (ii) the influence of inert gas in the feed on SRG was also proposed and studied. SGFR and reaction temperatures were found to have the considerable influence on the equilibrium composition of the products and solid carbon

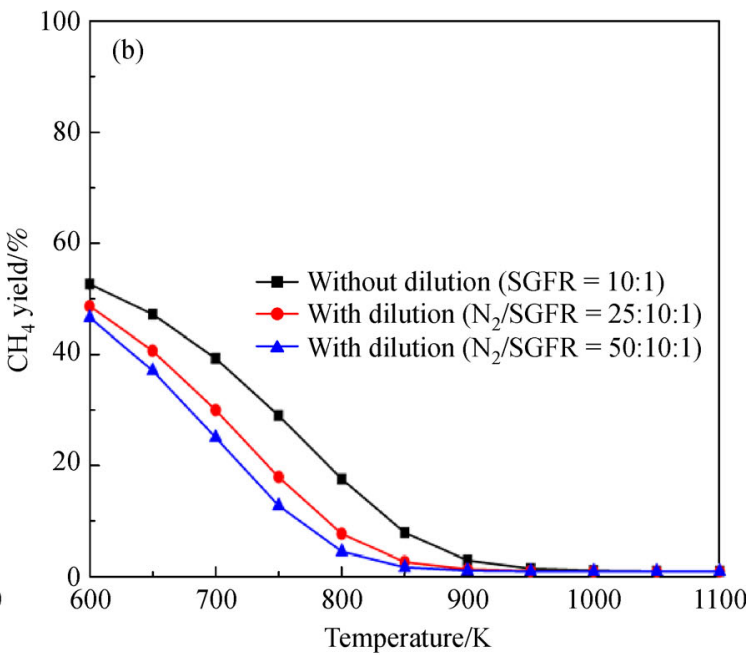

Fig. 8 Effect of $\mathrm{N}_{2}$ dilution of the feed on (a) $\mathrm{H}_{2}$ yield and (b) $\mathrm{CH}_{4}$ yield as a function of reaction temperature at equilibrium. 
formation. An increase in temperature favoured $\mathrm{H}_{2}$ production, however, operating at temperatures $<900 \mathrm{~K}$, $\mathrm{CO}_{2}$ and $\mathrm{CH}_{4}$ production prevailed due to the exothermic nature of WGS and methanation reactions, alongside SRG reaction. Furthermore, as the amount of SGFR increases the selectivity of $\mathrm{H}_{2}$ is favoured under steam rich conditions. Reactions regarding carbon formation were considered; decomposition of $\mathrm{CH}_{4}$ and $\mathrm{CO}$ and the reduction of $\mathrm{CO}$ and $\mathrm{CO}_{2}$. As the decomposition of $\mathrm{CH}_{4}$ is much involved in carbon deposition at high temperature $(>950 \mathrm{~K})$ and low SGFR $(<5: 1)$ during SRG, the carbon-free region can be achieved at high SGFR (10:1). The optimised equilibrium conditions which favoured SRG for $\mathrm{H}_{2}$ production are within the temperature range of $900 \mathrm{~K}-1050 \mathrm{~K}$, SGFR 10:1 and atmospheric pressure, respectively. At these reforming conditions, $\mathrm{CH}_{4}$ production (as the major competing reaction against the $\mathrm{H}_{2}$ formation) is minimised and carbon formation is thermodynamically inhibited. Regarding the introduction of inert gas to dilute the reactant partial pressure, when $\mathrm{N}_{2}$ gas is used at a specified ratio $(25: 10: 1)$, the equilibrium yield of $\mathrm{H}_{2}$ was improved under steam rich condition.

Acknowledgements This project has received funding from European Union's Horizon 2020 research and innovation programme under grant agreement No. 872102. Ammaru Ismaila thanks the financial support by the Petroleum Technology Development Fund (PTDF) Nigeria for his PhD research at The University of Manchester (File No. PTDF/ED/OSS/PHD/IA/ 1209/17).

Electronic Supplementary Material Supplementary material is available in the online version of this article at https://doi.org/10.1007/s11705-020$1975-0$ and is accessible for authorized users.

Open Access This article is licensed under a Creative Commons Attribution 4.0 International License, which permits use, sharing, adaptation, distribution and reproduction in any medium or format, as long as you give appropriate credit to the original author(s) and the source, provide a link to the Creative Commons licence, and indicate if changes were made. The images or other third party material in this article are included in the article's Creative Commons licence, unless indicated otherwise in a credit line to the material. If material is not included in the article's Creative Commons licence and your intended use is not permitted by statutory regulation or exceeds the permitted use, you will need to obtain permission directly from the copyright holder. To view a copy of this licence, visit http://creativecommons.org/licenses/by/4.0/.

\section{References}

1. Papageridis K N, Siakavelas G, Charisiou N D, Avraam D G, Tzounis L, Kousi K, Goula M A. Comparative study of Ni, Co, Cu supported on $\gamma$-alumina catalysts for hydrogen production via the glycerol steam reforming reaction. Fuel Processing Technology, 2016, 152: 156-175

2. Zhou C H, Zhao H, Tong D S, Wu L M, Yu W H. Recent advances in catalytic conversion of glycerol. Catalysis Reviews, 2013, 55(4): 369-453

3. Buffoni I N, Pompeo F, Santori G F, Nichio N N. Nickel catalysts applied in steam reforming of glycerol for hydrogen production.
Catalysis Communications, 2009, 10(13): 1656-1660

4. Wang W. Thermodynamic analysis of glycerol partial oxidation for hydrogen production. Fuel Processing Technology, 2010, 91(11): 1401-1408

5. Yang G, Yu H, Peng F, Wang H, Yang J, Xie D. Thermodynamic analysis of hydrogen generation via oxidative steam reforming of glycerol. Renewable Energy, 2011, 36(8): 2120-2127

6. Avasthi K S, Reddy R N, Patel S. Challenges in the production of hydrogen from glycerol - a biodiesel byproduct via steam reforming process. Procedia Engineering, 2013, 51: 423-429

7. Schwengber C A, Alves H J, Schaffner R A, da Silva F A, Sequinel R, Bach V R, Ferracin R J. Overview of glycerol reforming for hydrogen production. Renewable \& Sustainable Energy Reviews, 2016, 58: 259-266

8. Dou B, Song Y, Wang C, Chen H, Xu Y. Hydrogen production from catalytic steam reforming of biodiesel byproduct glycerol: issues and challenges. Renewable \& Sustainable Energy Reviews, 2014, 30: 950-960

9. Bagnato G, Iulianelli A, Sanna A, Basile A. Glycerol production and transformation: a critical review with particular emphasis on glycerol reforming reaction for producing hydrogen in conventional and membrane reactors. Membranes, 2017, 7(2): 17

10. Roslan N A, Abidin S Z, Ideris A, Vo D V N. A review on glycerol reforming processes over $\mathrm{Ni}$-based catalyst for hydrogen and syngas productions. International Journal of Hydrogen Energy, 2020, 45 (36): 18466-18489

11. Chen H, Ding Y, Cong N T, Dou B, Dupont V, Ghadiri M, Williams P T. A comparative study on hydrogen production from steamglycerol reforming: thermodynamics and experimental. Renewable Energy, 2011, 36(2): 779-788

12. Silva J M, Soria M A, Madeira L M. Thermodynamic analysis of glycerol steam reforming for hydrogen production with in situ hydrogen and carbon dioxide separation. Journal of Power Sources, 2015, 273: 423-430

13. Lin K H, Lin W H, Hsiao C H, Chang H F, Chang A C C. Hydrogen production in steam reforming of glycerol by conventional and membrane reactors. International Journal of Hydrogen Energy, 2012, 37(18): 13770-13776

14. Iulianelli A, Seelam P K, Liguori S, Longo T, Keiski R, Calabrò V, Basile A. Hydrogen production for PEM fuel cell by gas phase reforming of glycerol as byproduct of bio-diesel. The use of a Pd-Ag membrane reactor at middle reaction temperature. International Journal of Hydrogen Energy, 2011, 36(6): 3827-3834

15. Silva J M, Soria M A, Madeira L M. Challenges and strategies for optimization of glycerol steam reforming process. Renewable \& Sustainable Energy Reviews, 2015, 42: 1187-1213

16. Adhikari S, Fernando S D, Haryanto A. Hydrogen production from glycerin by steam reforming over nickel catalysts. Renewable Energy, 2008, 33(5): 1097-1100

17. Adhikari S, Fernando S, Gwaltney S, Filipto S, Markbricka R, Steele P, Haryanto A. A thermodynamic analysis of hydrogen production by steam reforming of glycerol. International Journal of Hydrogen Energy, 2007, 32(14): 2875-2880

18. Wang X, Li M, Wang M, Wang H, Li S, Wang S, Ma X. Thermodynamic analysis of glycerol dry reforming for hydrogen and synthesis gas production. Fuel, 2009, 88(11): 2148-2153 
19. Wang H, Wang X, Li M, Li S, Wang S, Ma X. Thermodynamic analysis of hydrogen production from glycerol autothermal reforming. International Journal of Hydrogen Energy, 2009, 34(14): 56835690

20. Li J, Yu H, Yang G, Peng F, Xie D, Wang H, Yang J. Steam reforming of oxygenate fuels for hydrogen production: a thermodynamic study. Energy \& Fuels, 2011, 25(6): 2643-2650

21. Fasolini A, Cespi D, Tabanelli T, Cucciniello R, Cavani F. Hydrogen from renewables: a case study of glycerol reforming. Catalysts, 2019, 9(9): 772

22. Smith J M, Van Ness H C, Abbott M M. Introduction to Chemical Engineering Thermodynamics. 7th ed. New York: McGraw-Hill, 2005, 450-508

23. Tahir M, Mulewa W, Amin N A S, Zakaria Z Y. Thermodynamic and experimental analysis on ethanol steam reforming for hydrogen production over Ni-modified $\mathrm{TiO}_{2} / \mathrm{MMT}$ nanoclay catalyst. Energy Conversion and Management, 2017, 154: 25-37

24. ChemCAD process simulator. Version 6.5.6. Houston, TX: Chemstations, Inc., 2012

25. Nikoo M K, Amin N A S. Thermodynamic analysis of carbon dioxide reforming of methane in view of solid carbon formation. Fuel Processing Technology, 2011, 92(3): 678-691
26. Cheng C K, Foo S Y, Adesina A A. Thermodynamic analysis of glycerol-steam reforming in the presence of $\mathrm{CO}_{2}$ or $\mathrm{H}_{2}$ as carbon gasifying agent. International Journal of Hydrogen Energy, 2012, 37 (13): 10101-10110

27. Charisiou N D, Papageridis K N, Siakavelas G, Tzounis L, Kousi K, Baker M A, Hinder S J, Sebastian V, Polychronopoulou K, Goula M A. Glycerol steam reforming for hydrogen production over nickel supported on alumina, zirconia and silica catalysts. Topics in Catalysis, 2017, 60(15-16): 1226-1250

28. Charisiou N D, Polychronopoulou K, Asif A, Goula M A. The potential of glycerol and phenol towards $\mathrm{H}_{2}$ production using steam reforming reaction: a review. Surface and Coatings Technology, 2018, 352: 92-111

29. Cantelo R C. The thermal decomposition of methane. Journal of Physical Chemistry, 1924, 28(10): 1036-1048

30. Gallo A, Pirovano C, Ferrini P, Marelli M, Psaro R, Santangelo S, Faggio G, Dal Santo V. Influence of reaction parameters on the activity of ruthenium based catalysts for glycerol steam reforming. Applied Catalysis B: Environmental, 2012, 121-122: 40-49

31. Sundari R, Vaidya P D. Reaction kinetics of glycerol steam reforming using a $\mathrm{Ru} / \mathrm{Al}_{2} \mathrm{O}_{3}$ catalyst. Energy \& Fuels, 2012, 26(7): 4195-4204 